\title{
Histopathological changes induced by ambient ammonia (ammonium sulphate) on the opercular linings of the catfish Heteropneustes fossilis
}

\author{
V. I. Paul, T. K. Banerjee * \\ Histochemistry \& Histopathology Laboratory, Centre of Advanced Study in Zoology, Banaras Hindu University, \\ Varanasi 221005 , India
}

\begin{abstract}
Acute toxicity of $2 \mathrm{~g} \mathrm{l}^{-1}$ ( $\left.\mathrm{LC}_{50}\right)$ ammonium sulphate on the outer and inner epithelial linings of the operculum of the air-breathing catfish Heteropneustes fossilis (Bloch) at different intervals of exposure was studied using histochemical techniques. The inner and outer epithelial linings showed different responses to the corrosive action of the inorganic fertilizer The outer epithelial lining exhibited massive and quicker damage due to necrosis and sloughing of its surface epithelial cells along with degeneration and disappearance of the club cells. Simultaneous regeneration of various cellular elements of the epidermis was also observed There were comparatively very few necrotic changes in the cellular constituents of the inner epithelial lining The alterations observed include hyperplasia of the epithelial cells (which showed accumulation of glycogen granules) and periodic increases followed by decreases in the density and size of the goblet mucous cells.
\end{abstract}

KEY WORDS: Heteropneustes fossilis - Opercular epidermis - Ammonia toxicity Ammonium sulphate Histopathology

\section{INTRODUCTION}

Inorganic fertilizers are used in association with organic manures to increase the natural productivity of ponds. However, indiscriminate use of inorganic fertilizers including ammonium sulphate, which releases ammonia (both $\mathrm{NH}_{3}$ and $\mathrm{NH}_{4}{ }^{+}$), has created numerous environmental hazards for fish populations (Soderberg et al. 1983, Lang et al. 1987, Ram \& Sathyanesan 1987, Sarkar 1991, Varadachari 1992), as these fertilizers contaminate neighbouring bodies of water, where they are mixed with run-off from agricultural fields. Although workers differ in their opinions regarding the optimal recommended dose of ammonium sulphate for aquaculture (Lakshmanan et al. 1971, Jhingran 1983, Sarkar 1991), on the Indian subcontinent the quantity of this fertilizer used in actual practice quite often surpasses the dosages recommended for aquacultural as well as for agricultural purposes, thus caus-

\footnotetext{
- Addressee for correspondence.

E-mail: tarun@banaras.ernet.in
}

ing extensive ammonia pollution. This inadvertent overdosing is due to lack of adequate training of fish farmers. Sarkar \& Konar (1985) and Sarkar (1991) have clearly demonstrated the harmful effects of overdosing of ammonium sulphate on fish production in culture ponds. Similarly, ammonium sulphate used to fertilize paddy fields is also hazardous to the species cultivated in those fields. Heteropneustes fossilis (Bloch), which is an integral part of paddy field culture on this subcontinent, is also subjected to severe ammonia toxicity from ammonium fertilizers during the intensive fertilization of the crop fields. No scientific checks to restrict the indiscriminate use of ammonium salts have yet been devised due to a lack of sufficient statistical data indicating the harmfulness of inorganic fertilizers. Therefore, in order to fill this information gap, a series of experiments was planned so that, in due course, farmers can be provided with scientific guidelines to help them avoid overdosing with inorganic fertilizers. Recently, Banerjee (1993) analysed the lethal toxicity of ammonium sulphate to the freshwater catfish $H$. fossilis. Subsequently, efforts have also been made to 
determine the lethal as well as the sublethal toxicity of this salt at the tissue level. The skin and the gills of fish, which are the outermost defence against the surrounding environment, come into direct contact with irritants including this salt. Mittal \& Mumshi (1971) have described the structural organization of the general body skin of $H$. fossilis. However, the outer and inner epidermal linings of the operculum differ greatly in their histological appearance. While the outer opercular lining, which appears identical to that of general body skin described by Mittal \& Munshi (1971), is made up of polygonal epithelial cells (ECs), goblet mucous cells (MCs) and large-sized club cells (CCs) with a few migrating leucocytes infiltrating the basal layer, the inner opercular lining is a simplified structure and is made up of ECs, MCs and a few wandering cells. Studies related to the opercular epidermis are scarce (Degnan et al. 1977, Karnaky \& Kinter 1977, Karnaky et al. 1977, Rajan \& Banerjee 1992). Hence, in this paper efforts have been made to illustrate the histopathological alterations induced by this inorganic fertilizer on the epidermal covering of the inner as well as on the outer surface of the operculum because the operculum, being the gill cover (Lagler et al. 1962), also provides protection for the delicate gills, probably with the help of the extensive mucogenic activity of its epithelial linings (Rajan \& Banerjee 1992, Paul \& Banerjee 1996).

\section{MATERIALS AND METHODS}

Healthy mixed sex specimens of Heteropneustes fossilis 20 to $23 \mathrm{~cm}$ in length and 45 to $50 \mathrm{~g}$ in body weight belonging to a single population were collected from a local fish dealer at Varanasi, Uttar Pradesh, India, and kept for $4 \mathrm{wk}$ in large plastic aquaria containing $50 \mathrm{l}$ of tap water for acclimation under confined laboratory conditions. They were liberally fed on minced goat liver on every alternate day. Water was renewed after every $24 \mathrm{~h}$ with routine cleaning of the aquaria, leaving no faecal matter, dead fish (if any) or unconsumed food. Prior to the commencement of the experiment, a $96 \mathrm{~h}$ median lethal concentration $(96 \mathrm{~h}$ $\mathrm{LC}_{50}$ ) value for ammonium sulphate $(99 \%$ pure, $\mathrm{E}$ Merck India, Bombay) was estimated following the trimmed Spearman Karber method (Hamilton et al. 1977), applying the 24 h renewal bioassay system, and was found to be $2 \mathrm{~g} \mathrm{l}^{-1}$ after $5 \%$ trimming. The total ammonia nitrogen in the lethal concentration medium was measured following APHA et al. (1985) and was found to be $8 \mathrm{mg} \mathrm{l}^{-1}$

For histopathological analysis, 20 groups of 10 fish each were treated with $2 \mathrm{~g} \mathrm{l}^{-1}$ ammonium sulphate (96 h $\mathrm{LC}_{50}$ ) solution. Each group of 10 fish ( $\times 20$ groups) was exposed to 50.1 of the toxicant medium (test solution) in a separate plastic aquarium. The test solution was prepared by dissolving ammonium sulphate thoroughly $\left(2 \mathrm{~g} \mathrm{l}^{-1}\right)$ in tap water $\left(6 \mathrm{mg} \mathrm{l^{-1 }}\right.$ dissolved oxygen, $\mathrm{pH} 7.5$, hardness $23.2 \mathrm{mg} \mathrm{l}^{-1}$ and water temperature $22 \pm 1^{\circ} \mathrm{C}$ ). A more extensive characterization of the water quality was not considered essential because only the relative differences between control and experimental fish were assessed.

Twenty control groups of 10 fish each were also kept in separate aquaria containing $50 \mathrm{l}$ of tap water without the addition of ammonium sulphate. Feeding was discontinued $24 \mathrm{~h}$ prior to the commencement of the experiment in experimental as well as in control groups with starvation continuing for the duration of the acute exposure experiment. However, at $24 \mathrm{~h}$ intervals, the fluid in each aquarium of each group was replaced with the appropriate, freshly prepared solution.

After $0,6,12$ and $24 \mathrm{~h}$ and after $2,3,4,6,8$, and $10 \mathrm{~d}$ of exposure, 5 fish from the experimental aquaria as well as from control aquaria were sacrificed for microscopic examination by sudden spinal dislocation. The remaining fish (if any) in these control/experimental aquaria were discarded. For experiments beyond $96 \mathrm{~h}$ ( $\mathrm{LC}_{50}$ time) at each stage, fish were sacrificed randomly from the surviving members of the remaining aquaria.

Opercula from both sides were surgically removed, rinsed in physiological saline and immersed immediately in the respective fixative solution. The operculum from the right side of each fish was fixed in $10 \%$ neutral formalin and the left operculum of each fish was cut transversely into 2 equal halves, one for fixation in Bouin's fluid and the other for fixation in Helly's fluid. All tissues were dehydrated in graded ethanal, cleared in xylene/cedar wood oil and embedded in paraffin. All histological procedures were performed at room temperature following procedures described in Lillie (1954), Gurr (1958) and Pearse (1985)

Glycoproteins and mucopolysaccharides were histochemically detected by periodic acid-Schiff (PAS) (McManus 1946) and by alcian blue pH 2.5 (AB 2.5) and $A B$ 2.5/PAS dual staining (Pearse 1985). Sulphated mucosubstances and glycosaminoglycans were localized by the alcian blue pH 1.0 (AB 1.0) technique (Lev \& Spicer 1964). The Bismarck brown technique was also used for the selective visualization of water resistant mucoproteins (Leach 1947). PAS with prior treatment with salivary amylase was used to confirm the presence of glycogen (Pearse 1985).

Paraffin sections (6 $\mathrm{mm}$ thickness) from all of the 5 sacrificed fish of each stage (control as well as experimental) were stained with Ehrlich's haematoxylin and/or Heidenhain's iron haematoxylin and eosin (H\&E) techniques (Lillie 1954, Gurr 1958). However, 
histopathological analyses were carried out for only 3 control and 3 experimental fish at each time. The thickness of the epidermis was measured using an ocular meter and a stage micrometer. Other morphometric analyses were performed following Rajan \& Banerjee (1992) and Paul \& Banerjee (1996) (see Figs. 3, 4 \& 6). Standard statistical analyses based on random sampling from 10 different, non-overlapping stained sections from each of the 5 fish from the experimental and control groups were performed.
For multiple comparison, 1-way analyses of variance (ANOVA) followed by Duncan's multiple range test, were also performed following Bruning \& Kintz (1977). Since the differences between the measurements taken from various control groups at different time intervals of exposure were not significant, averages of all the control groups were taken into consideration. Similarly, $0 \mathrm{~h}$ exposure data appeared identical to those of control fish; hence, this data is not described separately.
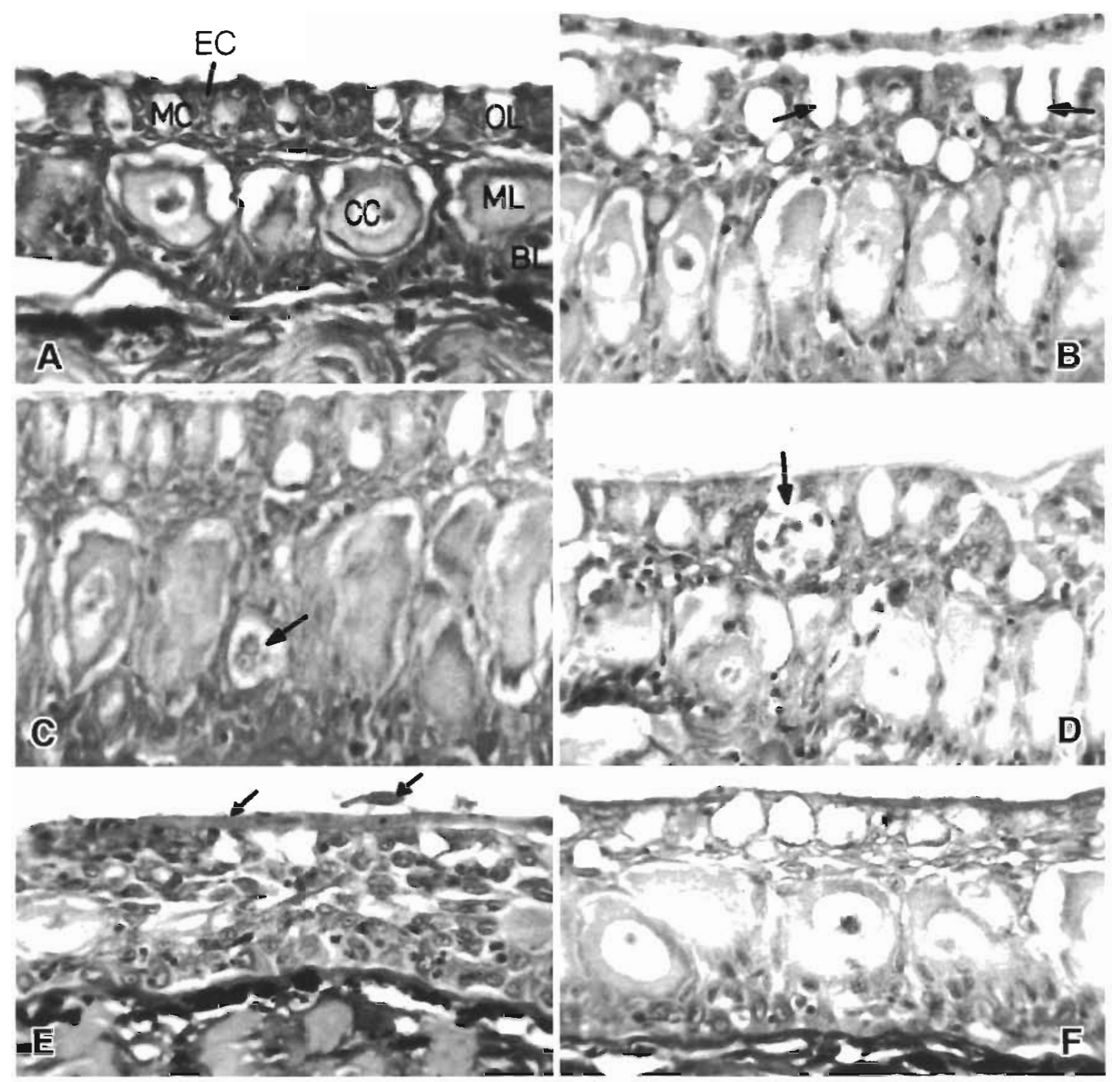

Fig. 1. Hepteropneustes fossilis. (A) Part of the outer opercular epidermis of a control fish. $\mathrm{H} \& \mathrm{E}, \times 514 . \mathrm{BL}=\mathrm{basal}$ layer; $\mathrm{CC}=\mathrm{club}$ cell; $\mathrm{EC}=$ polygonal epithelial cell; $\mathrm{MC}=$ mucous cell; $\mathrm{ML}=$ middle layer; $\mathrm{OL}=$ outer layer. $(\mathrm{B}-\mathrm{F}$ ) Vertical sections of outer opercular epidermis showing histopathological alterations caused by acute ammonium sulphate exposure at different intervals of time. H\&E, $\times 514$. (B) Deposition of thick layer of the eosinophilic material containing pyknotic nuclei of degenerating cells and blood material after $6 \mathrm{~h}$ of exposure. Note the actively secreting mucocytes (arrows). (C) A CC containing a small amount of cytoplasmic material after $2 \mathrm{~d}$ of exposure. Note the prominent healthy nuclei (arrow). (D) Infiltration of phagocytes into a degenerating $\mathrm{CC}$ (arrow) after $3 \mathrm{~d}$ of exposure. Note the deposition of a thick layer of slime on the surface. (E) Loosening of cell junctions between ECs after $4 \mathrm{~d}$ of exposure. Note the disappearance of the CCs due to their degeneration and deposition of slime over the surface (arrows). (F) Regeneration of epidermis after $10 \mathrm{~d}$ of exposure (similar in appearance to that of the control, cf. Fig. $1 \mathrm{~A}$ ) 


\section{RESULTS}

\section{Outer epidermal lining}

\section{Control epidermis}

The epidermis covering the outer surface of the operculum may arbitrarily be divided into 3 layers, an outermost, a middle and a basal layer (Fig. 1A). The outermost layer was made up of 4 to 5 layers of compactly arranged flat or rectangular ECs whose spindleshaped nuclei were darkly stained. The middle layer was a single row of large, round closely approximated
CCs, with centrally placed, prominent (one or more) vacuoles and usually with 2 nuclei. Between the adjacent CCs there were vertically compressed flat filamentous ECs, whose darkly stained nuclei appeared to be compressed laterally. The innermost layer was a single layer of low columnar basal cells in between which the lymphocytes were found. The epidermal lining at the distal end of the operculum (branchio-stegal membrane) was generally composed of undifferentiated ECs.

The sac-like MCs, which were usually located between the ECs of the outermost layer, reacted weakly

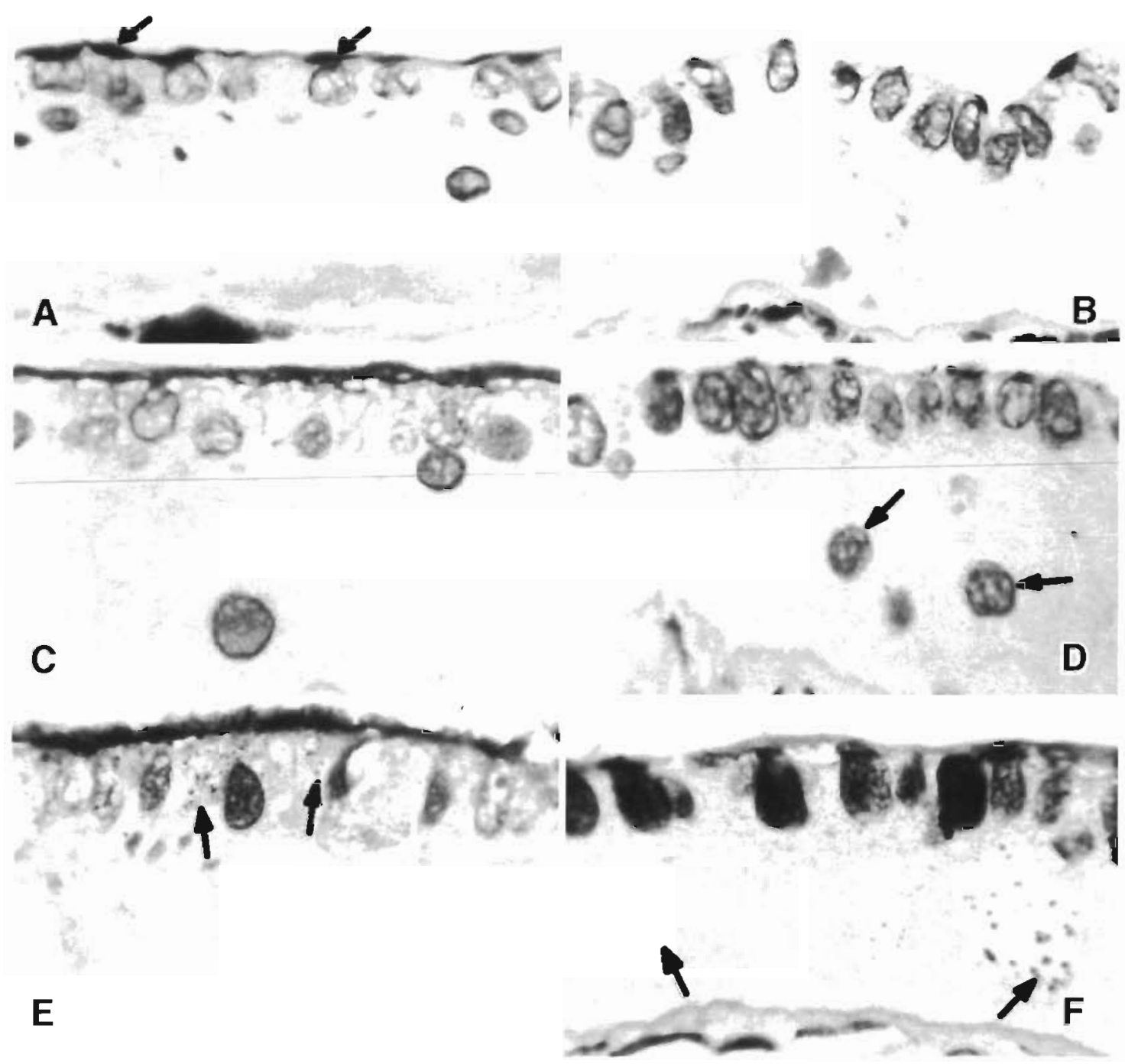

Fig. 2. Hepteropneustes fossilis. (A) Part of the outer opercular epidermis of control fish showing normal carbohydrate histochemistry and distribution of mucous cells (MCs). Note the slimy coating (arrows). AB 2.5/PAS, $\times 514$. (B-F) Histopathological alterations in the distribution of MCs and carbohydrate histochemistry in the outer opercular epidermis due to acute ammonium sulphate exposure at various time intervals. (B) Loss of the slimy coating after $6 \mathrm{~h}$ of exposure. AB 2.5/PAS, $\times 514$. (C) Active elaboration of a thick layer of slime by MCs after $1 / 2 \mathrm{~d}$ of exposure. Note decreased MC density. AB 2.5/PAS, $\times 514$. (D) Increase in the density of MCs after $2 d$ of exposure due to their regeneration in the lower layers (arrows). AB 2.5/PAS, $\times 514$. (E) Secretion of a thick slumy coating over the body surface after $3 \mathrm{~d}$ of treatment. Note the deposition of glycogen granules in the ECs (arrows) of the OL and ML PAS, $\times 514$. (F) Deposition of coarse granules of glycogen in the CCs (arrows) after 6 d of exposure. PAS, $\times 514$ 
to moderately with PAS and moderately to strongly with $\mathrm{AB} 2.5$, with their peripheries staining more strongly (Fig 2A). With AB 2.5/PAS, they appeared more greenish-blue than red. Certain other carbohydrate histochemical findings from control as well as from experimental tissues are shown in Table 1

\section{Experimental epidermis}

A thin layer of sloughed eosinophilic PAS-negative substance bearing red blood corpuscles (RBC) and other degenerating cells with pyknotic nuclei started to appear after $6 \mathrm{~h}$ of treatment (Fig. 1B). The ECs at the surface became round and swollen and had prominent, lightly stained nuclei which contained chromatin materials compacted at several places to dark coarse granules, and after $2 \mathrm{~d}$ the ECs became columnar. After $4 \mathrm{~d}$ inter-cellular junctions between the ECs in the outermost layer widened due to extra-cellular vac- uolization, and the epithelium appeared spongy (Fig $1 E)$. After $8 d$ the damage became very pronounced Subsequently, the epidermis regenerated and after 10 d looked more or less identical to that of the control (Figs. 1F, 3 \& 4). Ammonium salt treatment also caused the appearance of fine glycogen granules in the ECs of the middle and outermost layers of the epidermis, especially after $3 \mathrm{~d}$ of exposure (Fig. 2E, Table 1).

The basal cells also showed periodic decreases followed by increases in their height at different stages of exposure. This decrease in height perhaps represented a post-mitotic stage of the basal cells following the generation of new populations to replace the sloughed ones at the surface. The slimy superficial coating observed in the control fish disappeared after $6 \mathrm{~h}$ of treatment (Fig. 2B). Simultaneously, these MCs emptied their contents on the surface (Fig. 2C) and disappeared, causing a decrease in MC density after $12 \mathrm{~h}$. Later there were periodic fluctuations in the MC population (Fig. 2D), and after $3 \mathrm{~d}$ the MCs voided their con-

Table 1. Hepteropneustes fossilis. Summary of histochemical alterations in the carbohydrate contents of the various cell types in the outer opercular epidermis at various time intervals of acute ammonium sulphate exposure. $\mathrm{AB} 2.5=$ alcian blue $\mathrm{pH} 2.5 ; \mathrm{AB} 1.0$ $=$ alcian blue $\mathrm{pH} 1.0 ; \mathrm{BB}=$ Bismarck brown; $\mathrm{ECs}=$ epithelial cells; $\mathrm{CC}$ s = club cells; $\mathrm{MCs}=$ mucous cells (peripheries/secretory contents); $\mathrm{ML}=$ middle layer; $\mathrm{OL}=$ outermost layer; $\mathrm{PAS}=$ periodic acid - Schiff $; \mathrm{S}=$ secretory coating. $-=$ negative staining; \pm faint or doubtful reaction; $1+=$ weak staining; $2+=$ moderate staining; $3+=$ strong staining. $1^{\circ}=$ very small quantity; $2^{\circ}=$ small quantity; $3^{\circ}=$ moderate quantity; $4^{*}=$ substantially larger quantity

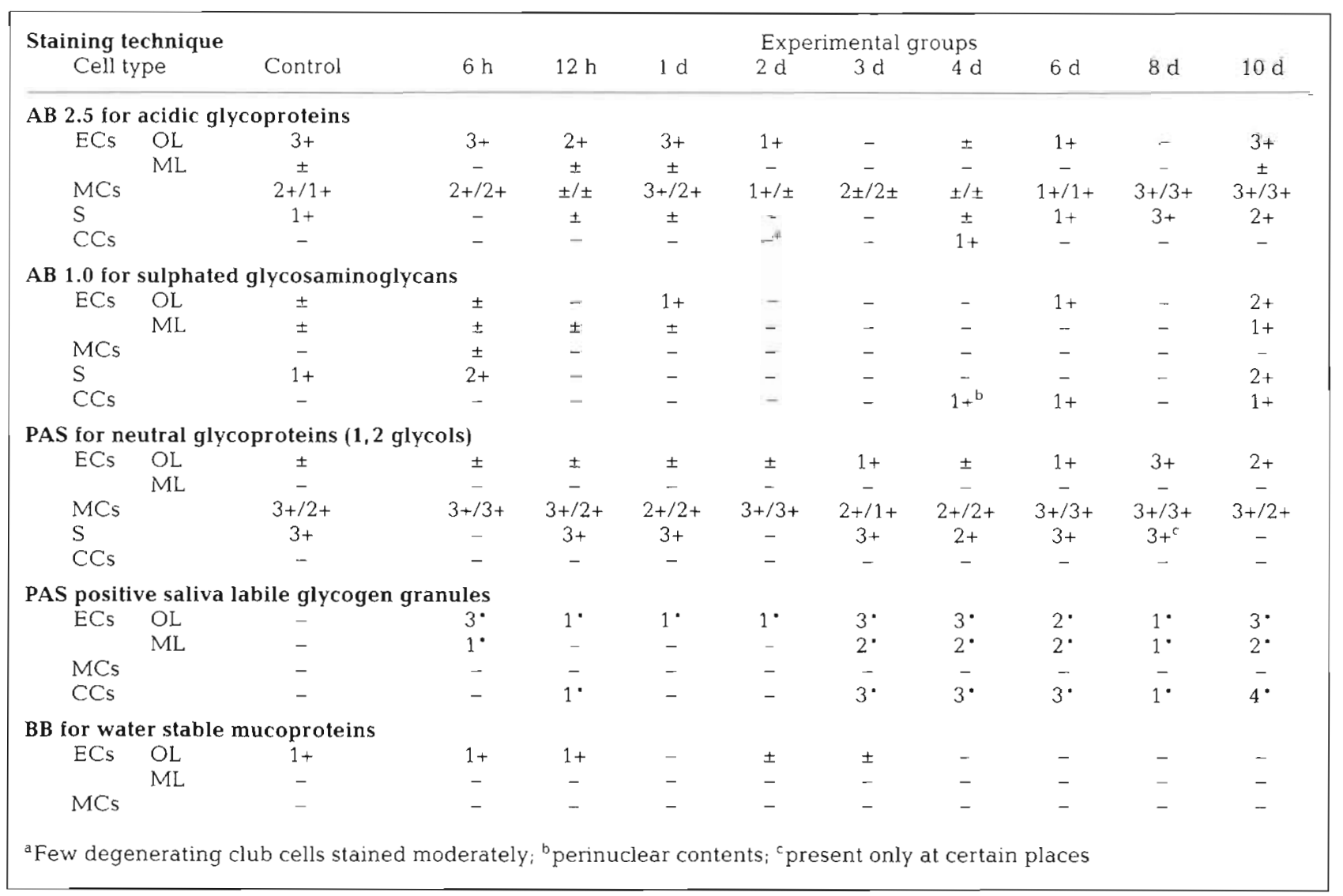




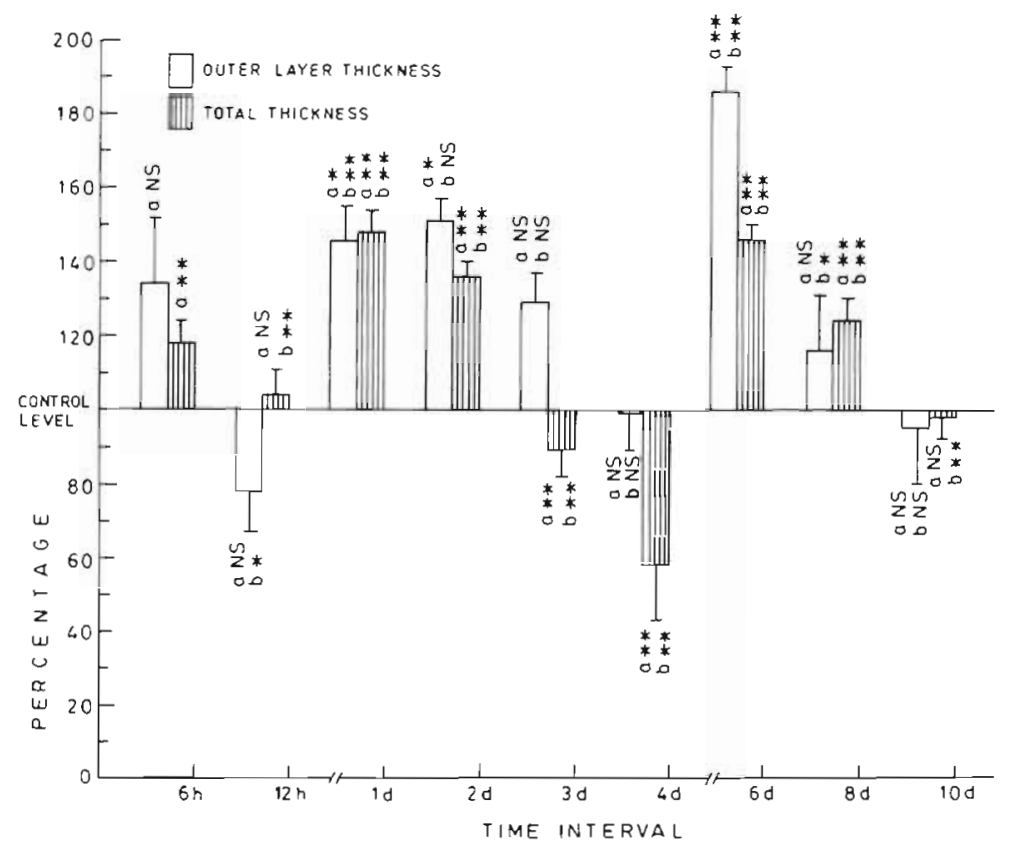

Fig. 3. Hepteropneustes fossilis. Alterations (given as percentages of control values) in the average outer layer thickness of outer opercular epidermis and average total thickness of outer opercular epidermis at various time intervals of acute ammonium sulphate exposure $e_{i} \bar{x} \pm$ SEM. $(" p<0.05 ; " p<0.01$; $N S=$ not significant; based on Duncan's multiple range test; $\mathrm{a}=$ between respective experimental group and control group $i b=$ between the respective experimental group and the preceding experimental group)

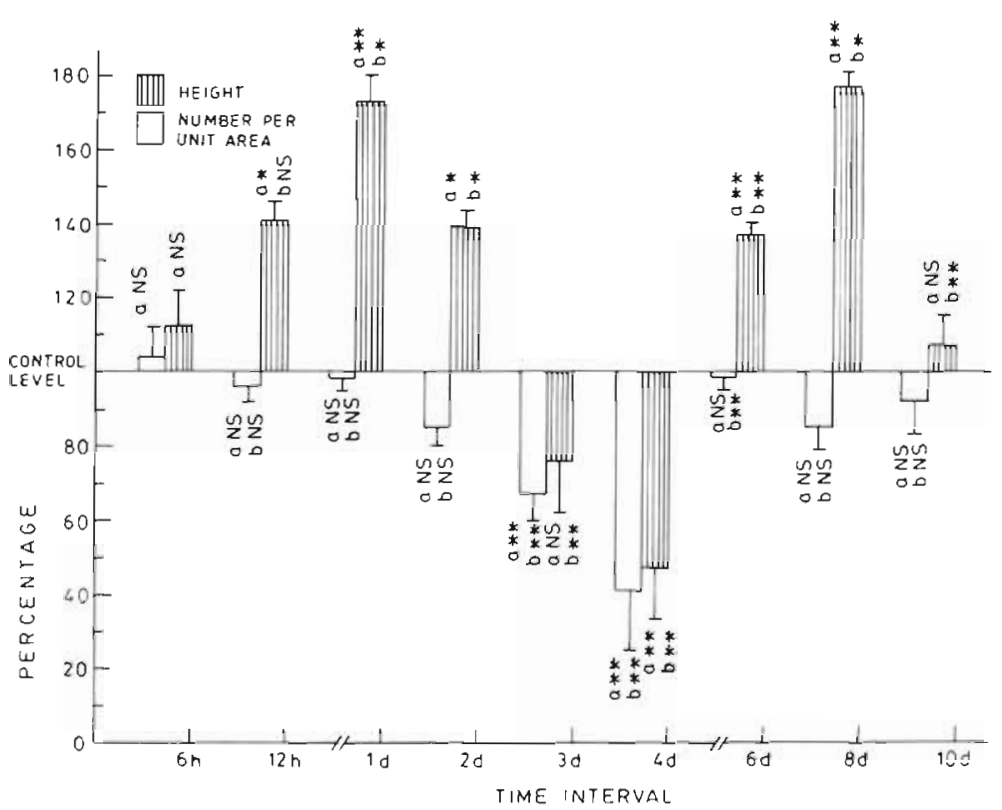

Fig. 4. Hepteropneustes fossilis. Alterations (given as percentages of control values) in average height of club cells and average number (density) of club cells per unit area in the outer opercular epidermis at various time intervals of acute ammonium sulphate exposure; $\bar{x} \pm$ SEM. $(" p<0.05 ; \cdots p<$ 0.01; NS: not significant; based on Duncan's multiple range test; $a=b e$ tween respective experimental group and control group; $b=$ between the respective experimental group and the preceding experimental group) tents to form a thick coating of PAS-positive slime (Figs, 1D \& 2E). Developing MCs were sometimes also observed in the basal and middle layers during this period. In the subsequent stages there were several periodic increases followed by decreases in the number of MCs, and after $10 \mathrm{~d}$, their distribution appeared more or less similar to that found in the control groups (Fig. 1F). The ECs of the outermost layer also secreted a small amount of slime in varying quantities at several stages of treatment (Table 1). The staining properties of the carbohydrate moieties of MCs also showed periodic alterations at different stages of exposure (Table 1). These cells remained empty and vacuolated up to $12 \mathrm{~h}$ of exposure.

Necrosis of the CCs started with the appearance of a prominent central vacuole in the middle of these cells where a small amount of ground substance and the nuclei remained lodged. After $1 \mathrm{~d}$, prominent peripheral vacuoles also appeared below the cell boundaries. Side by side, a second tier of small-sized CCs regenerated in the middle layer during this period. After $2 \mathrm{~d}$, these cells elongated vertically and formed a single layer (Figs. 1C \& 4). A number of $\mathrm{CCs}$ showing necrosis were also commonly observed. After $3 \mathrm{~d}$, most CCs were arranged in a single row in the middle layer with only a few degenerating CCs still remaining in the outermost layer. The degenerating CCs were often infiltrated with a large number of phagocytes (Fig. 1D). Even though the CCs also degenerated (Fig. 1E) in the subsequent stages, regeneration took place after $6 \mathrm{~d}$ (Fig. 4), and after $8 \mathrm{~d}$ the MCs were arranged in 2 layers. After $10 \mathrm{~d}$ the epidermis appeared more or less similar to that of the control fish (Figs. $1 F \& 4)$. Fine glycogen granules were also observed in the CCs (Fig. 2F) at several stages of exposure (Table 1)

\section{Inner epidermal lining}

\section{Control epidermis}

In contrast to the general body surface and the outer opercular epidermis, the inner epithelial lining did not possess any CCs and the epidermis appeared very thin 
(Fig. 5A). The remaining cell types and their distributions were more or less identical to that of the outer covering, with ECs constituting the main bulk of the outermost layer. The MCs were restricted mainly to the outermost layer (Figs. 5A, C). The middle layer was made up of flat or spindle-shaped ECs along with a few sac-like MCs. Basal cells constituted the innermost layer of the epidermis, with a few wandering cells enclosed in prominent lymphatic spaces. The carbohydrate histochemistry and staining intensity of the various cell types were significantly different from those of the outer epithelial lining (Tables $1 \& 2$ ).

\section{Experimental epidermis}

The ECs showed hyperplasia after $2 \mathrm{~d}$ of treatment. Thereafter, the epidermis remained thick (Figs. 5B \& 6) except after $3 \mathrm{~d}$. The ECs of the outermost layer showed a faint PAS and weak $A B 2.5$ reaction in most of the stages of exposure (Table 2). However, after 10 $d$, the AB 2.5 reaction appeared more or less identical to that of the control group (Table 2). The ECs accumulated varying quantities of glycogen granules at different stages of exposure (Fig 5F, Table 2). New MCs appeared in the outermost layer and their density in creased after $2 \mathrm{~d}$ (Fig. 5D). The number of MCs decreasd after $3 \mathrm{~d}$ (Fig. 5E) and thereafter their population showed periodic alterations in density. The mucous coating over the surface also showed qualitative as well as quantitative changes at various stages of exposure (Table 2).

Other carbohydrate histochemical changes noticed in the various cell types at various experimental stages in relation to the control have been detailed in Table 2.
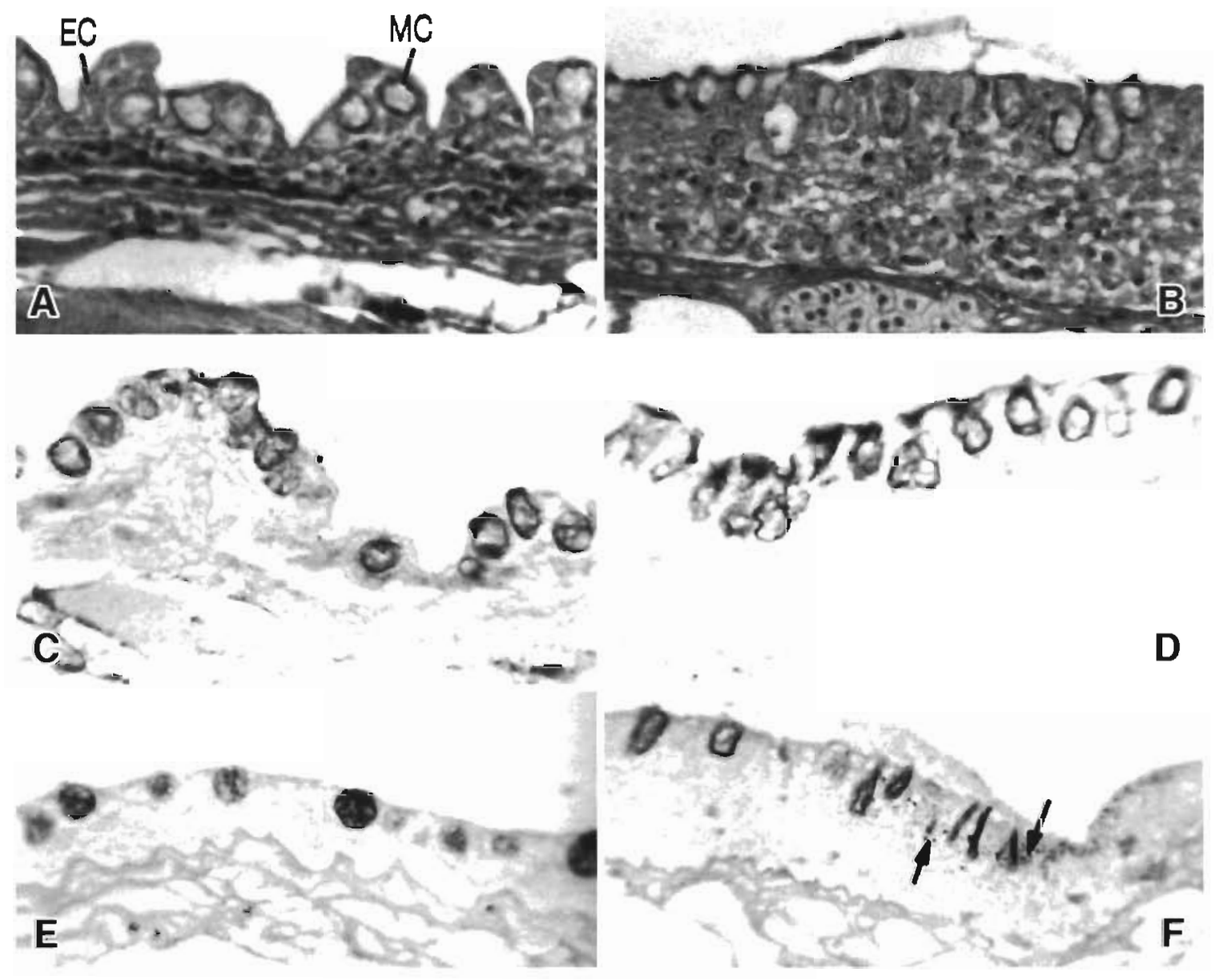

Fig. 5. Hepteropneustes fossilis. (A) Part of the inner opercular epidermis of control fish. H\&E, $\times 514$. EC = polygonal epithelial cell; $\mathrm{MC}=$ mucous cell. (B) Severe hyperplasia causing increase in the thickness of the inner epidermis after $6 \mathrm{~d}$ of exposure. Note sloughing at the surface. $H \& E, \times 514$. (C) Part of the inner opercular epidermis of the control fish showing the distribution of MCs and normal carbohydrate histochemistry. AB 2.5/PAS, $\times 514 .(D-F)$ Histopathological alterations caused by acute ammonium sulphate in the carbohydrate staining and $\mathrm{MC}$ distribution on the inner opercular epidermis at various time intervals. (D) Increase in the densily of MCs after $2 \mathrm{~d}$ of treatment. $\mathrm{AB} 2.5 / \mathrm{PAS}, \times 514$. (E) Decrease in the density of MCs after $3 \mathrm{~d}$ of exposure. $\mathrm{AB} 2.5 / \mathrm{PAS}, \times 514$. (F) Deposition of granular glycogen in the ECs after $6 \mathrm{~d}$ of treatment (arrows). PAS, $\times 514$ 
Table 2. Hepteropneustes fossilis. Summary of histochemical alterations in the carbohydrate contents of the various cell types in the inner opercular epidermis at various intervals of acute ammonium sulphate exposure. AB $2.5=$ alcian blue pH $2.5 ; \mathrm{AB} 1.0=\mathrm{al}-$ clan blue pH 1.0; $\mathrm{BB}=$ Bismarck brown $\mathrm{ECs}=$ epithelial cells; $\mathrm{MCs}=$ mucous cells (peripheries/secretory contents); $\mathrm{ML}=\mathrm{middle}$

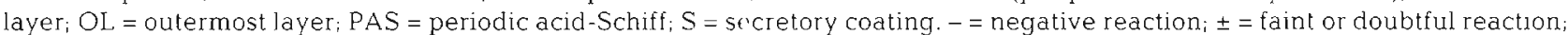
$1+=$ weak stalning; $2+=$ moderate staining; $3+=$ strong staining. $1^{\circ}=$ very small quantity; $2^{\circ}=$ small quantity; $3^{\circ}=$ moderate quantity; $4^{*}=$ substantially larger quantity

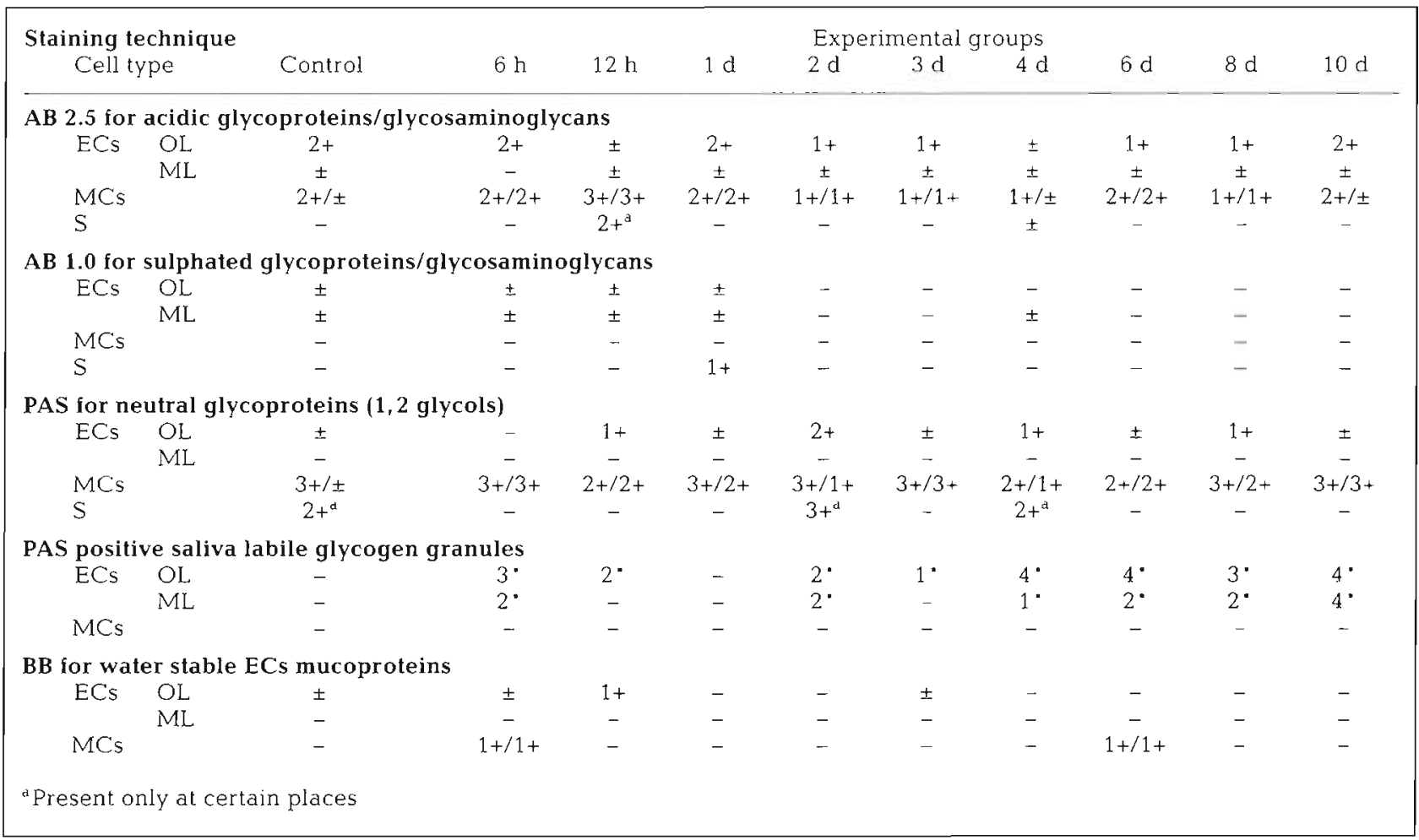

\section{DISCUSSION}

On exposure, the mucous coating which covers the outer surface of the epidermis is immediately lost. However, a coating of non-carbohydrate exudate of slightly eosinophilic material continues to protect the epidermis. Loss of the mucous coating from the surface stimulates the regeneration of a large batch of MCs, causing increased MC density (number). Soon thereafter, these MCs release their contents as a thick protective coating in an attempt to reduce the toxicity of the ammonium salt but, due to continued toxicity of the irritant, many are lost, causing a substantial decrease in their population. Alterations in the morphometric measurements of MCs following exposure to ammonium sulphate have been extensively dealt with by Paul \& Banerjee (1996). While studying the effect of acid stress, Zuchelkowski et al. $(1981,1986)$ also noticed hyperplasia of the epidermal MCs of the brown bull head catfish Ictalurus nebulosus following acid exposure. Acid stress also causes the loss of sexual dimorphism, as observed in the MCs of control fish (Zuchelkowski et al. 1986). However, in Hetero- pneustes fossilis no suct. sexual dimorphism has been reported by any previous researchers, either in the control fish (Mittal \& Munshi 1971) or in stressed fish with various xenobiotics (Rajan \& Banerjee 1991, Banerjee \& Paul 1993, Hemalatha \& Banerjee 1993).

One important function of the gill cover (operculum) (Lagler et al. 1962) is to protect the delicate gills, which are the main organs of respiration. (The main function is ventilatory movement causing water flow via the gill chamber.) The present investigation clearly shows that the inner epithelial lining of the operculum has good mucogenic potential as evidenced by the presence of a dense $M C$ population and by the strong reaction for carbohydrates observed in the ECs of the most superficial layer. The inner epidermal lining secretes a profuse quantity of slime in comparison to that produced by the general body surface (Rajan \& Banergee 1992, Banerjee \& Paul 1993) and the outer epithelial covering of the operculum (present investigation). The continuous flow of water through the opercular chambers which provides an exchange of oxygen probably aggravates the risk of additional exposure of the gills to the ambient pollutants. The continuous secretion of 


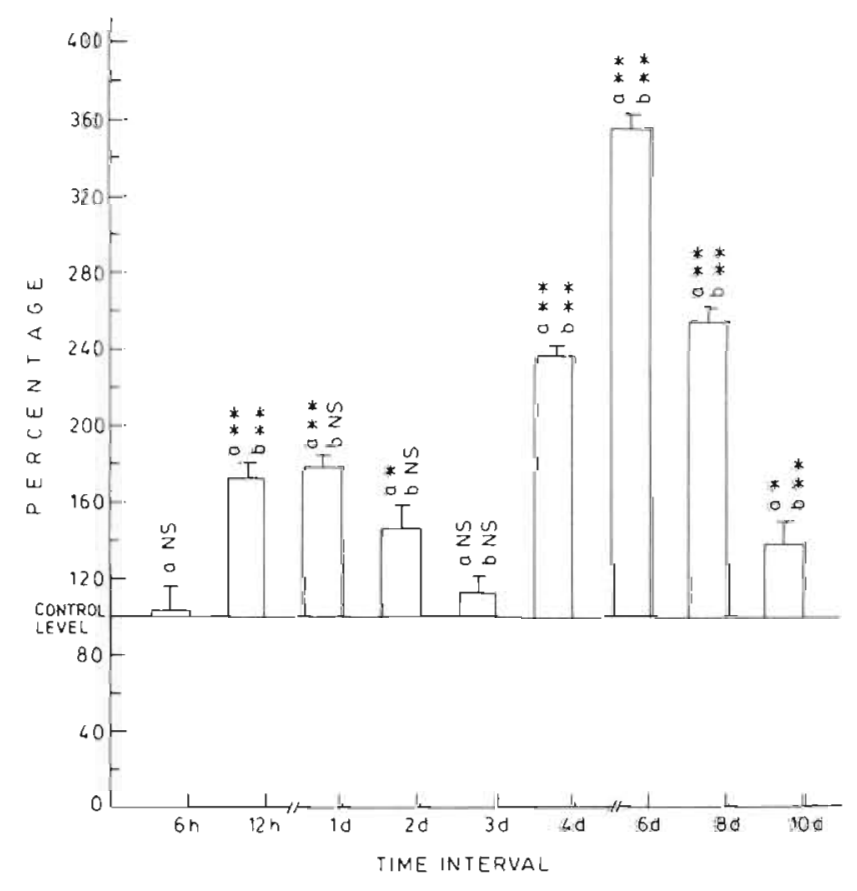

Fig. 6. Hepteropneustes fossilis. Alterations in the percentage of average total thickness of the inner opercular epidermis at various time intervals of acute ammonium sulphate exposure $\bar{x} \pm$ SEM. Control value is considered as $100 \%(\cdot p<0.05$; $\cdots p<0.01 ; \mathrm{NS}=$ not significant; based on Duncan's multiple range test; $a=$ between respective experimental group and control group; $b=$ between the respective experimental group and the preceding experimental group)

slime by the gills and by the inner opercular lining might provide an important safety coating for the gills since slime is known to act as a lubricant and to provide mechanical protection, has an osmoregulatory function, prevents colonization of parasites, fungi, and bacteria, and contains various types of compounds that can support several chemical and immunological reactions (Van Oosten 1957, Fletcher \& Grant 1969, Rosen \& Cornford 1971, Cameron \& Endean 1973, Pickering 1974). According to Arillo \& Melodia (1990), fish mucus constitutes a kind of barrier between a fish and its environment and some mucus components may have a de-toxifying function counteracting ambient toxins.

The slimy secretion of the inner epithelial lining of the operculum contains varying quantities of glycosaminoglycans in addition to the conventional glycoproteins. In contrast to the epidermis of the general body surface (Rajan \& Banerjee 1992, Banerjee \& Paul 1993) and the epithelial lining of the outer surface of the operculum (present study), the ECs of the inner opercular lining show enhanced staining with AB 1.0 at several stages of acute ammonium sulphate exposure. Since glycosaminoglycans are known to play important roles in the maintenance of the viscosity of extracellular ground substances (Muir 1980), their presence might render the slime (within the opercular chamber) more viscous, thereby protecting the gills more effectively for a longer period and thus delaying the penetration of ambient pollutants. This might delay the damage due to the deleterious effects of the toxicants. Zuchelkowski et al. (1985) also observed an apparent shift towards increased sulfomucin production in the epidermal MCs of acid-stressed Ictalurus nebulosus (Lesueur) and suggested that the functional significance of increased sulfomucin production may be related to maintenance of ionic equilibrium. Due to the active flow of water across the gills, which is necessary for respiration, the risk that slimy secretions of the opercular epidermis will be continuously washed away is also much greater than in the case of general body skin. Exposure to various xenobiotics causes increased ventilatory movement by the operculum and a greater ventilation (water) volume which results in respiratory efficiency (Flis 1968a, b. Sausa \& Meade 1977. Smart 1978, Hillaby \& Randall 1979, Lang et al. 1987). This aggravates the loss of slime due to sloughing. The addition of water-stable mucoproteins to the slime (Table 2) may delay this loss considerably by facilitating greater retention of mucus. This delicate mechanism for slime retention, however, collapses following prolonged continuous exposure to ambient ammonium salt. The negative reaction with Bismarck brown for water-stable mucoprotein shown by the epidermis of the general body skin (Banerjee \& Paul 1993) also supports this view.

In response to the corrosive action of the ammonium salt, the ECs also show periodic secretory activities. Following secretion, exhaustion and renewal, the ECs as well as the MCs show an increase followed by a decrease in staining intensities. The oedematous swelling and the appearance of vacuoles in the various components of the epidermis during the present investigation might be important signs of necrosis prior to cell death, induced by ammonium sulphate treatment. Decreased followed by increased thickness of the epidermis at different stages suggests its degenerating and regenerating stages respectively (Figs. 3 \& 6). Variation in thickness is also brought about by increased or decreased density/volume of the various cell types (Fig. 4).

It is interesting to note that the ECs of the inner opercular lining do not show much sign of cellular necrosis or sloughing following exposure to acute ammonium sulphate solution. On the other hand, the general body surface shows extensive damage due to exposure to ammonium salt (Banerjee \& Paul 1993) and the outer lining of the operculum shows minor degenerative changes (present study). This indicates that the inner lining of the operculum has a better and more effective protective device against the ambient toxicants than 
the outer opercular and general body surface, probably due to more efficient mucogenic activity. The inner lining of the operculum, which provides the second line of protection for the opercular chamber. exhibits less damage.

The normal opercular epidermis of Heteropneustes fossilis contains no glycogen granules, which indicates that its consituent cells are in a metabolically active state and are engaged in mucogenic activity. The presence of large quantities of glycogen in the ECs of the ammonium sulphate-treated $H$. fossilis skin is significant, as this might imply a disturbed respiratory pathway within these cells due to a marked swelling of the cells caused by ammonium sulphate. A similar swelling of ECs which had accumulated glycogen due to hyperosmotic stress caused by $1 \%$ sodium chloride treatment was also observed in the epidermis of Barbus sophor by Agarwal et al. (1979), who attributed it to the disturbed mucogenesis and/or kertinization. The presence of glycogen in the CCs of the ammonium sulphate-treated eipdermis of $H$. fossilis is significant since the ammonium salt grossly disturbs the proteinaceous nature of the otherwise protein-rich CCs, thereby altering their normal function.

Acknowledgements. This research was supported by the University Grants Commission (Govt. of India) Research Project No. F3-68/89 (SR II). One of the authors (V.I.P.) thanks C.S.I.R., New Delhi, for financial assistance in the form of a Senior Research Fellowship.

\section{LITERATURE CITED}

Agarwal SK, Banerjee TK, Mittal AK (1979) Physiological adaptation in relation to hyperosmotic stress in the epidermis of a fresh-water teleost Barbus sophor (Cyprinidae, Cypriniformes): a histochemical study. Z Mikrosk Anat Forsch 9:51-64

APHA (American Public Health Association), American Water Works Association, Water Pollution Control Federa. tion. (1985) Standard methods for the examination of water and waste water, 16th edn. American Public Health Association, Washington, DC

Arillo A, Melodia F (1990) Protective effect of fish mucus against Cr VI pollution. Chemosphere 20:397-402

Banerjee TK (1993) Estimation of acute toxicity of ammonium sulphate to the fresh-water catfish. Heteropneustes fossulis I. Analysis of $\mathrm{LC}_{50}$ values determined by various methods. Biomed Environ Sci 6:31-36

Banerjee TK, Paul VI (1983) Estimation of acute toxicity of ammonium sulphate to a fresh water catfish Heteropneustes fossilis II. A histopathological analysis of epidermis. Biomed Environ Sci 6:45-58

Bruning JL, Kintz BL (1977) Computational handbook of statistics, 2nd edn. Scott, Foresman and Company, Glenview, Illinois, p 1-308

Cameron AM, Endean R (1973) Epidermal secretions and the evolution of venom glands in fishes. Toxicon 11:401-410
Degnan KJ, Karnaky KJ Jr, Zadunaisky JA (1977) Active chloride transport in the in vitro opercular skin of a teleost (Fundulus heteroclitus), a gill-like epithelium rich in chloride cells. J Physiol (Lond) 271:155-1.92

Fletcher TC, Giant PT (1969) Immunoglobulins in the serum and mucus of the plaice, Pleuronectes platessa. Biochem. $\mathrm{J}$ $115: 65$

Flis J (1968a) Anatomico-histopathological changes induced in carp (Cyprinus carpio) by ammonia water. I. Effects of toxic concentrations. Acta Hydrobiol 10:205-224

Flis J (1968b) Anatomico-histopathological changes induced in carp (Cyprinus carpio) by ammonia water. II. Effects of subtoxic concentrations. Acta Hydrobiol 10:225-238

Gurr E (1958) A practical manual of medical and biological staining techniques. Interscience Publishers Inc., New York

Hamilton MA, Russo RC, Thurston RV (1977) Trimmed spearman karber method for estimating median lethal concentration in toxicity bioassays. Environ Sci Technnol 11:714-719

Hemalatha S, Banerjee TK (1993) Acute toxicity of the heavy metal zinc (a trace element) on the mucous cells of the airsac (a modified gill structure) of the air-breathing catfish, Heteropneustes fossilis (Bloch). J Freshwater Biol 5:233-240

Hillaby BA, Randall DJ (1979) Acute ammonia toxicity and ammonia excretion in rainbow trout (Salmo gairdneri). J Fish Res Bd Can 36:621-629

Jhingran VG (1983) Fish and fisheries of India. Hindustan Publishing Corporation, New Delhi

Karnaky KL Jr, Degnan KJ, Zadunaisky JA (1977) Chloride transport across isolated opercular epithelium of Killifish: a membrame rich in chloride cells. Science 195:203-205

Karnaky KJ Jr, Kinter WB (1977) Killi fish opercular skin. A flat epithelium with a high density of chloride cells. J Exp Zool 199:355-364

Lagler KF, Bardach JE, Miller RR (1962) Ichthyology. John Wiley and Sons Inc, New York

Lakshmanan MAV, Sukumaran KK, Murty DS, Chakraborty DP, Philipose MT (1971) Preliminary observations on intensive fish farming in fresh water ponds by the composite culture of Indian and exotic species. J Inl Fish Soc India $2: 1-21$

Lang $T$, Peters $G$, Hoffmann R, Meyer E (1987) Experimental investigations on the ventilation frequency growth, epidermal mucous cells, and gill strucutre of rainbow trout Salmo gairdneri. Dis Aquat Org 3:159-165

Leach EH (1947) Bismarck brown as a stain for mucoproteins. Stain Technol 22:73

Lev R, Spicer SS (1964) Specific staining of sulphated groups with alcian blue at low pH. J Histochem Cytochem 12:309

Lillie RD (1954) Histopathological techniques and practical histochemistry. The Blackistan Division, McGraw-Hill, New York

McManus JFA (1946) Histological demonstration of mucin after periodic acid. Nature 158:202

Mittal AK, Munshi JSD (1971) A comprative study of the structure of the skin of certain air breathing fresh water teleosts. J Zool, Lond 163:515-532

Muir IHM (1980) The chemistry of the ground substance of joint cartilages. In: Sololoff $L$ (ed) The joints and synovial fluid. II. Academic Press, New York, p 27-94

Paul VI, Banerjee TK (1996) Analysis of ammonium sulphate toxicity in the fresh water catfish Heteropneustes fossilis using mucocyte indexing. Pol Arch Hybrobiol 43: in press

Pearse AGE (1985) Histochemistry theoretical and applied, Vol. II. Churchill Livingstone Inc., New York 
Pickering AD (1974) The distributions of mucous cells in the epidermis of the brown trout Salmo trutta (L) and char Salvelinus alpinus (L.). J Fish Biol 6:111-118

Rajan MT, Banerjee TK (1991) Histopathological changes induced by acute toxicity of mercuric chloride on the epidermis of a fresh water catfish, Heteropneustes fossilis (Bloch). Ecotoxicol Environ Saf 22:139-152

Rajan MT, Banerjee TK (1992) Acute toxic effect of mercuric chloride on the mucocytes of the epithelial lining of the accessory respiratory organ and skin of the air breathing catfish Heteropneustes fossilis (Bloch) Biomed Environ Sci 5:325-335

Ram RN, Sathyanesan AG (1987) Histopathological changes in liver and thyroid of the teleost fish, Channa punctatus. in response to ammonium sulphate fertilizer treatment. Ecotoxicol Environ Saf 13:185-190

Rosen MV, Conford NE (1971) Fluid friction of the fish slime. Nature 234:49-51

Sarkar SK (1991) Use of ammonium sulphate nitrate in rearing major carp spawn. Geobios 18:177-181

Sarkar SK, Konar SK (1985) Effects of ammonium sulphate on behaviour, survival, feeding, growth and reproduction of fish. Environ Ecol 3:312-316

Smart GR (1978) Investigation of the toxic mechanisms of ammonia to fish gas exchange in rainbow trout (Salmo

Responsible Subject Editor: C. B. Schreck, Corvallis, Oregon, USA gairdneri) exposed to acutely lethal concentration. J Fish Biol 12:93-104

Soderberg RW, Flynn JB, Schmittou HR (1983) Effects of ammonia on growth and survival of rainbow trout in intensive static water culture. Trans Am Fish Soc 112:448-451

Sousa RJ, Meade TL (1977) The influence of ammonia on oxygen delivery system of Coho salmon haemoglobin. Comp Biochem Physiol 58A:23-58

Van Oosten J (1957) The skin and scales. In: Brown ME (ed) The physiology of fishes, Vol. I. Academic Press, New York, p 207-244

Varadachari C (1992) Phosphoric acid, phosphates and fertilizers for the future. Proc Indian Natl Sci Acad 58B:119-126

Zuchelkowski EM, Lantz RC. Hintron DE (1981) Effects of acid stress on epidermal mucous cells of the brown bull head Ictalurus nebulosus (Le Sueur): a morphometric study. Anat Rec 200:33-39

Zuchelkowski EM, Lantz RC, Hinton DE (1986) Skin mucous cells response to acid stress in male and female brown bull head catfish, Ictalurus nebulosus (Le Sucur). Aquat Toxicol 8:139-148

Zuchelkowski EM, Pinkstaff CA, Hinton DE (1985) Mucosubstance Histochemistry in control and acid stressed epidermis of brown bull head catfish Ictalurus nebulosus (Lesueur). Anat Rec 212:327-335

Manuscript first received: March 25, 1995

Revised version accepted: September 27, 1996 